\title{
Effects of sulfuric acid promoter on biopolymer-derived fractions from empty plam fruit bunch under solvothermal fractionation process
}

\author{
Nopparat Suriyachai ${ }^{1,4}$, Punjarat Khongchamnan ${ }^{2}$, Navadol Laosiripojana ${ }^{3,4}$, Torpong Kreetachat ${ }^{1}$, \\ Verawat Champreda ${ }^{4,5}$, Saksit Imman ${ }^{1,2 *}$ \\ ${ }^{1}$ Intregated Biorefinery excellent Center (IBC), School of Energy and Environment, University of Phayao, Tambon Maeka, Amphur Muang \\ Phayao 56000, Thailand, '2School of Energy and Environment, University of Phayao, Tambon Maeka, Amphur Muang Phayao 56000, \\ Thailand, ${ }^{3}$ The Joint Graduate School for Energy and Environment (JGSEE), King Mongkut's University of Technology Thonburi, Prachauthit \\ Road, Bangmod, Bangkok 10140, Thailand, ${ }^{4}$ BIOTEC-JGSEE Integrative Biorefinery Laboratory, National Center for Genetic Engineering \\ and Biotechnology, Innovation Cluster 2 Building, Thailand Science Park, Khlong Luang, Pathumthani 12120, Thailand, ${ }^{5}$ Enzyme Technology \\ Laboratory, National Center for Genetic Engineering and Biotechnology, Thailand Science Park, Khlong Luang, Pathumthani 12120, Thailand
}

\section{A B S T R A C T}

A single step sulfuric acid catalyzed $\left(\mathrm{H}_{2} \mathrm{SO}_{4}\right)$ under the organosolv process was studied for fractionation of empty palm fruit branches. The use of $\mathrm{H}_{2} \mathrm{SO}_{4}$ as an acid catalyst showed higher efficiency of the removal of hemicellulose with an increase in lignin removal from native EPFB into organic phase and leave glucan in solid fraction. The optimal condition showed the maximum glucan yields of $2.45 \mathrm{~g}$ and the highest lignin yields of $1.86 \mathrm{~g}$ was at $180^{\circ} \mathrm{C}$, with $15 \mathrm{~min}$ residence time. The addition of $\mathrm{H}_{2} \mathrm{SO}_{4}$ catalyzed enhanced hemicellulose and lignin removal. $0.05 \% \mathrm{H}_{2} \mathrm{SO}_{4}$ led to improve glucan yields of $3.17 \mathrm{~g}$ with the lower degradation of glucan and pentose in the aqueous phase. Under this condition, a $1.28 \mathrm{~g}$ recovery of lignin was obtained from the organic phase. Physicochemical analysis revealed intact cellulose fibers with the decrease in crystallinity, while the hemicellulose was partially recovered as mono- and oligomeric sugar. High-purity organosolv lignin with $<2 \%$ sugar cross-contamination was obtained with no major structural modification according to Fourier-transform infrared spectroscopy. This work represents an alternative process for efficient fractionation of lignocellulosic biomass in biorefineries.

Keywords: Clean fractionation; Empty palm fruit bunch; Lignocelluloses; Solvothermal process

\section{INTRODUCTION}

Nowadays, energy crisis is an important issue in the world due to the decrease in fossil fuels. Moreover, the combustion of the fossil fuels is released pollutants into atmosphere (Perera et al., 2017). Furthermore, the increase in the population and the industrial development caused the higher energy consumption. In order to solve the problem, lignocellulose biomass has a performance to replace the conventional fossil fuels (Ahorsu et al., 2018).

The rapid growth of oil palm industry would be increased by 6 million ha in the year of 2030 especially for the area of developing country in South-East Asia. In Thailand, palm oil industry is predicted to create an agricultural waste as empty palm fruit bunch at approximately 16 ton per year
(Pangsang et al. 2019). A simple implementation on empty palm fruit bunch by burning result in a low heating value fuel as well as the main concern on air pollution [Chang et al., 2014]. This leads to the development of lignocellulosic palm waste as an alternative resource for bioproducts based on clean and eco-friendly technology [Hassan et al., 2019]. Lignocelluloses biomass is agricultural residue such as rice straw, corncob and empty palm fruit brunch (EPFB). These mainly consist of cellulose (30-50\%), hemicellulose (20-40\%), and lignin (10-30\%) (Arora et al., 2020). Among these components, lignin has considered as a value-added product from the fractionation process in the biorefinery application. Lignin is an aromatic polymer in lignocellulosic biomass, which composes of phenylpropanoid monomers, including coniferyl, sinapyl, and p-coumaryl alcohols. These structures bond together via $\mathrm{C}-\mathrm{O}$ chemical linkages (such as

\footnotetext{
${ }^{*}$ Corresponding author:

Saksit Imman, Intregated Biorefinery excellent Center (IBC), School of Energy and Environment, University of Phayao, Tambon Maeka, Amphur Muang Phayao 56000, Thailand, School of Energy and Environment, University of Phayao, Tambon Maeka, Amphur Muang Phayao 56000, Thailand, Tel: +66-8615-84845, E-mail: saksit.im@up.ac.th 
$\beta-\mathrm{O}-4, \alpha-\mathrm{O}-4,4-\mathrm{O}-5$, etc.) and C-C (Mathew et al., 2018), therefore, lignin is also regarded as the alternative resource to produce aromatic bio-chemicals (Tarasov et al., 2018). Structurally, lignin varies by species, subcellular location, plant tissue and methods of extraction. These extracted lignins are often denoted as technical lignins and different from native lignin physically and chemically. As a result, the mentioned significant differences in lignin structure, functionality, reactivity and heterogeneity, industrial utilization of this biopolymer present significant challenges (Cheng et al., 2012).

Biorefinery process is the industrial process, in which biopolymers are isolated and converted to biofuels and biomaterials. Several fractionation technologies have been developed for the primary step in the biorefinery of biomass, in which lignocellulosic components are fractionated. The organosolv process uses organic solvents to extracted lignin from biomass components, and is versatile to various types of biomass. Several organic solvents, such as alcohols (e.g., methanol and ethanol), esters, and ketones, have been explored for fractionation of different biomass materials. The efficiency of separating different biopolymers varies among solvents. The selection of solvent systems with desirable properties and selectivity is thus the basis in developing an organosolv process (Zhang et al., 2016).

Many researches have been studied for the utilization of EPFB with prior separation process e.g. organosolve (Grande et al., 2019), bisulfite (Tan et al., 2016, hotcompressed water (Pangsang et al. 2019), steam explosion (Medina et al., 2016), and acid/alkaline (Kim et al., 2012) for various bioproducts such as sugars (Lee et al., 2020; Nurfahmi et al., 2016) bioethanol (Pangsang et al. 2019) and biochemicals (Hafyan et al., 2020). Solvothermal process using a ternary mixture of solvents comprising a shortchain alcohol, methyl isobutyl ketone (MIBK) and water is reported as clean and effective method, which could be improved the performance by additional of homogeneous acid promoter such as sulfuric acid $\left(\mathrm{H}_{2} \mathrm{SO}_{4}\right)$, phosphoric acid $\left(\mathrm{H}_{3} \mathrm{PO}_{4}\right)$. This process has been studied for singlestep isolation of biomass components from variety of feedstocks (Takkellapati et al., 2018). In the fractionation process, the ternary mixture is disturbed via the addition of water, which allows the separation of aqueous-alcohol phase (hemicellulose-derived products) and lignin phase to the organic phase, while cellulose is obtained in the solid phase. Moreover, the addition of organic acids can play role as solvents and catalysts in the reaction mixture. (Delbecq et al., 2018).

In this work, a solvothermal process for fractionation of EPFB into respective components was investigated. The effects of varying key reaction parameters (temperature and acid concentrations) was studied based on the performance of fractionation process in term of yield and selectivity of cellulose and lignin fraction. Further physicochemical properties of the separated biopolymerderived fractions were analyzed. This work provided an improved approach for biomass fractionation in integrated biorefineries.

\section{MATERIALS AND METHODS}

\section{Materials}

Empty palm fruit branch (EPFB) was harvested from Ban soo village, Phayao province, Thailand, milled and passes through 0.5-0.085 mm size screen using Retch ZM200 (Retsch SM2000, Hann, Germany). The samples were dried at $65^{\circ} \mathrm{C}$ for $24 \mathrm{~h}$ to remove the moistures. The chemical composition of raw EPFB was analyzed according to the standard NREL protocal (Sluiter et al., 2008). The starting material contained $39.2 \%$ cellulose, $25.7 \%$ hemicellulose, $23.6 \%$ lignin, and $6.7 \%$ ash on a dry-weight basis. All chemical reagents were purchased from major chemical suppliers, i.e., Sigma-Aldrich, Merck, and Fluka.

\section{Empty palm fruit bunch fractionation}

The fractionation process was conducted according to previous study (Suriyachai et al., 2017). In brief, fractionation process was conducted in a $500-\mathrm{mL}$ pressurized reactor (Parr Reactor 4560, Parr instrument, Moline, IL, USA). Solvent ratio in the solvent mixture was set up according to the phase diagram to obtain a single-phase mixture (Klamrassamee et al., 2013). Solid and organic solvent ratio was $10 \mathrm{~g}$ of empty palm fruit brunch per $100 \mathrm{~mL}$ of single-phase mixture. Solvent mixture contained water $(50 \%)$, ethanol $(25 \%)$, methyl isobutyl ketone $(25 \%)$ and $0.5-0.2 \%$ of $\mathrm{H}_{2} \mathrm{SO}_{4}$. The reaction temperature $\left(160-200^{\circ} \mathrm{C}\right)$ was set up for residence time of $15 \mathrm{~min}$ with stirring at $100 \mathrm{rpm}$. The overview experiment of solvothermal fractionation process is illustrated in Fig. 1. The outputs (glucose yield and lignin recovery) of fractionation process were determined according to the previous description.

\section{Analytical methods}

All analytical methods were conducted according to the description of previous study (Suriyachai et al., 2017). In brief, three separated fractions were analyzed the properties in term of quantity and quality of products.

The solid fraction was analyzed the physiochemical properties of cellulose by Scanning electron microscopy analysis (SEM), X-ray diffraction analysis (XRD), and 


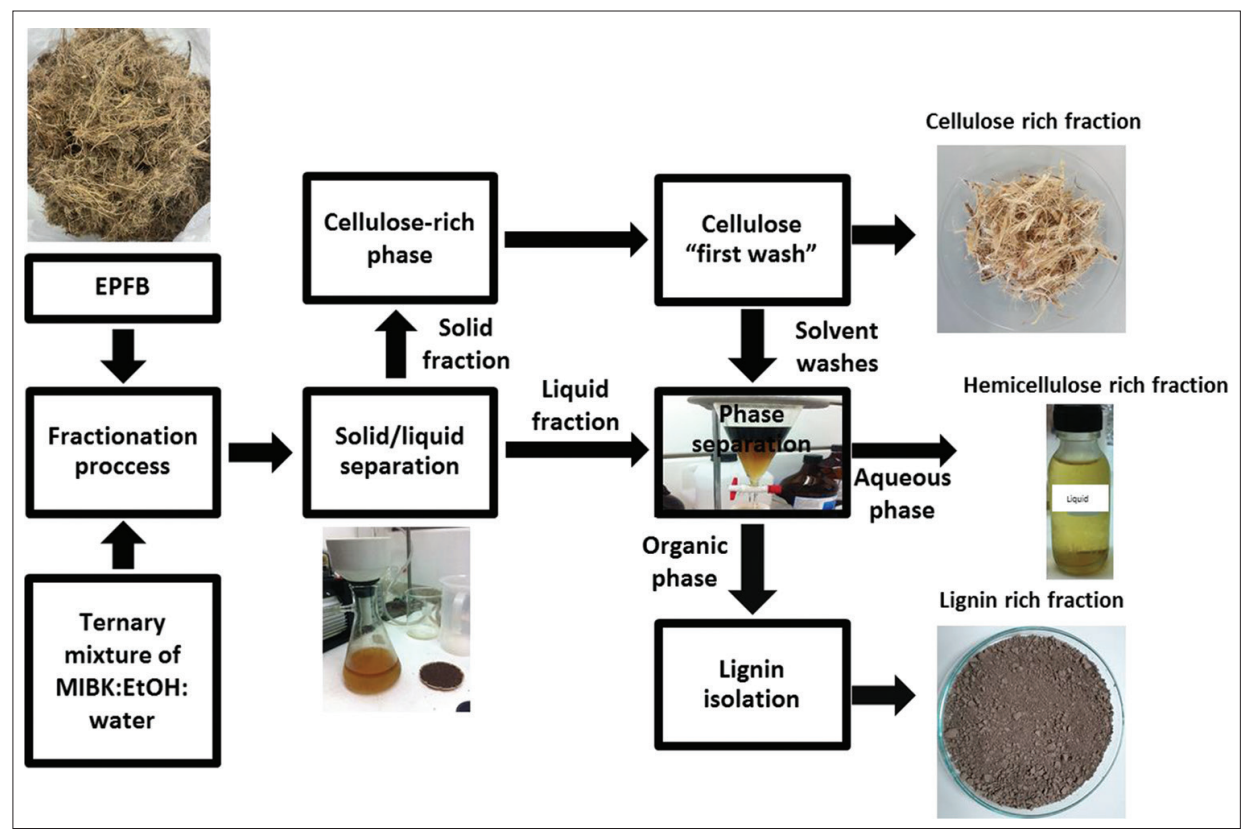

Fig 1. Overview of solvothermal fractionation process.

Brunauer, Emmett, and Teller (BET). SEM was operated by a JSM-6301F Scanning Electron Microscope (JEOL, Tokyo, Japan) with an electron beam energy of $5 \mathrm{kV}$ to observe the structure features. XRD was used an X'Pert PRO diffractometer (PANalytical, Almelo, The Netherlands) to determine the crystallinity index (CrI). The specific CrI was calculated according to the providing equation (Segal et al., 1959). BET was conducted by a Belsorp-max TPDpro (BEL Japan, Tokyo, Japan) with thermal conductivity detector (Semi-diffusion type, 4-element W-Re filament) to determine the available surface area.

The aqueous fraction was determined the soluble sugars profiles by High Performance Liquid Chromatograph (HPLC) using LDC Model 4100, Shimadzu, Kyoto, Japan, equipped with a refractive index and a UV-Vis detector and an Aminex HPX-87H column (Bio-Rad, Hercules, CA, USA), operating at $65^{\circ} \mathrm{C}$ with $5 \mathrm{mM} \mathrm{H}_{2} \mathrm{SO}_{4}$ as the mobile phase at a flow rate of $0.5 \mathrm{~mL} / \mathrm{min}$.

The isolated lignin was characterized the lignin properties during the fractionation process by Klason lignin, Molecular weight determination, and Fourier-transform infrared spectroscopy (FT-IR). Klason lignin expressed the purity of isolated lignin which analyzed according to NREL protocol. Molecular weight determination using a high-performance liquid chromatograph (HPLC) (WATER e2695, Waters, MA, USA), being equipped with an Agilent PLgel 10 um MIXED-B column. FT-IR using a Perkin-Elmer System 2000 (PerkinElmer, Waltham, MA, USA) to determine the functional group of aromatic compounds.

\section{RESULTS AND DISCUSSION}

Effects of acid concentration in fractionation process The effect of reaction temperature on the efficiency of fractionation of EPFB at various temperature from 160$200^{\circ} \mathrm{C}$ was firstly studied, as can be seen in Fig.2. In the solid phase, cellulose was the mainly products, being obtained after fractionation process. Cellulose yields of $2.11 \mathrm{~g}$ to $2.45 \mathrm{~g}$ were obtained from fractionation temperature of 160 to $180^{\circ} \mathrm{C}$, respectively. Temperature affected cellulose yields in solid residue, because high temperatures can damage chemical structures of lignin, and hemicellulose also caused the degradation of carbohydrates and lignin. On the other hand, sulfuric acid could catalyze hydrolysis of hemicelluloses as well. The increase in temperature from $160^{\circ} \mathrm{C}$ to $180^{\circ} \mathrm{C}$ led to boost hemicellulose and lignin removal from the native EPFB. However, increasing reaction temperature to $200{ }^{\circ} \mathrm{C}$ showed the significant $(p \leq 0.05)$ decrease in cellulose yields (1.64 g), as showed in Fig. 2a. Pentose yields were the major products found in the aqueous phase. Maximum pentose yields of $1.19 \mathrm{~g}$ was obtained at $200{ }^{\circ} \mathrm{C}$ for $15 \mathrm{~min}$. Moreover, increasing temperature led to enhance inhibitory by-products (HMF and furfural), being showed in Fig. 2b. The increase in HMF and furfural was observed due to the degradation of HMF and decomposition of the pentose sugar (xylose), which indicates an increase in the severity of the reaction conditions with higher temperature after long reaction time, resulting in higher by-products (Nopparat et al., 2018). The effects of temperature on lignin removal were showed in Fig. 2c. The highest lignin yields was $1.96 \mathrm{~g}$ under temperature of $200{ }^{\circ} \mathrm{C}$ for $15 \mathrm{~min}$. However, lignin 
yields obtained from organic phase under temperature of $180^{\circ} \mathrm{C}$ and $200^{\circ} \mathrm{C}$ are not significant different $(p>0.05)$. The fractionation condition of $180^{\circ} \mathrm{C}$ for $15 \mathrm{~min}$ was selected as the optimal condition for further experimental. It indicated that glucan yields in the isolated solid rank the first, followed by lignin yields obtaining in the aqueous-organic phase and pentose yields in aqueous phase. Moreover, the under optimal condition also showed higher purity of the main products in each fraction.

\section{Effect of $\mathrm{H}_{2} \mathrm{SO}_{4}$ Concentration on Products Yields}

The effects of $\mathrm{H}_{2} \mathrm{SO}_{4}$ concentration on glucan in the solid phase, pentose in the aqueous, and lignin obtaining from organic phase were showed in Fig.3 In the solid fraction, glucan is the major product. Glucan yields in the range of 1.46-3.17 $\mathrm{g}$ were obtained (Fig.2a). The highest glucan yields , $3.17 \mathrm{~g}$, was obtained under the condition of $180^{\circ} \mathrm{C}$ for $15 \mathrm{~min}$, with $0.05 \%$ of $\mathrm{H}_{2} \mathrm{SO}_{4}$. Glucan yields increased along with higher $\mathrm{H}_{2} \mathrm{SO}_{4}$ concentrations, because high acid concentration led to sugar degradation products (Wu et al., 2012). Maximum pentose yields were obtained from aqueous phase of $1.9 \mathrm{~g}$ at $180^{\circ} \mathrm{C}, 15 \mathrm{~min}$, and $0.1 \% \mathrm{H}_{2} \mathrm{SO}_{4}$. The highest lignin yields obtaining from organic phase was $2.1 \mathrm{~g}$ for $0.2 \% \mathrm{H}_{2} \mathrm{SO}_{4}$. Pentose and lignin were removed

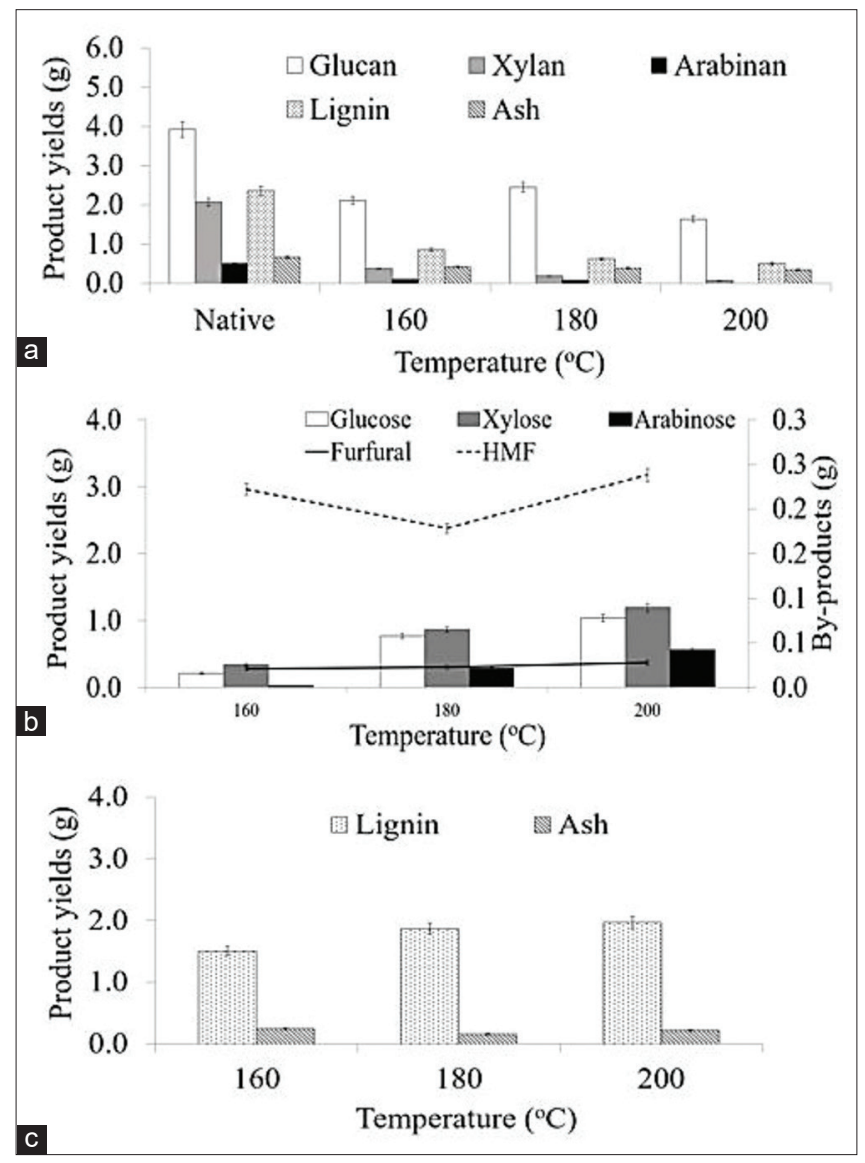

Fig 2. Effect of fractionation temperature on EPFB components: (a) solid phase, (b) aqueous phase, (c) organic phase. from the solid, because the acid concentration led to reduce pentose recovery, and increase in sugar degradation products in the aqueous phase. The degradation of high temperature resulted in the degradation of aromatic ring linkages between the lignin units like $\beta-\mathrm{O}-4 / \alpha-\mathrm{O}-4$, being found to be cleaved in lignin chemical structure (Brodeu et al., 2011). The use of $\mathrm{H}_{2} \mathrm{SO}_{4}$ in the ternary solvents mixture allowed to increase the cleaved rate of $\alpha$ - and $\beta$-ether linkages in lignin (Jasiukaityte et tal., 2020), and resulted in the dissolution of lignin fragments with lower molecular weights (Sebastien., 2019). As a result, it can increase hemicellulose dissolution under hydrothermal conditions and also swelling cellulose fibers (Cao et al., 2013). The previous study utilized agricultural residue under fractionation process to produce bio-material. (Klamrassamee et al., 2013) investigated fractionation process of eucalyptus wood chips with organosolv fractionation under $\mathrm{H}_{2} \mathrm{SO}_{4}$ promoters. Maximum glucan yields (in isolated solid), pentose yields (in aqueous phase), and lignin yields (in aqueous-organic phase) were $75.9 \%$, $17.8 \%$, and $13.7 \%$, respectively. In comparison with

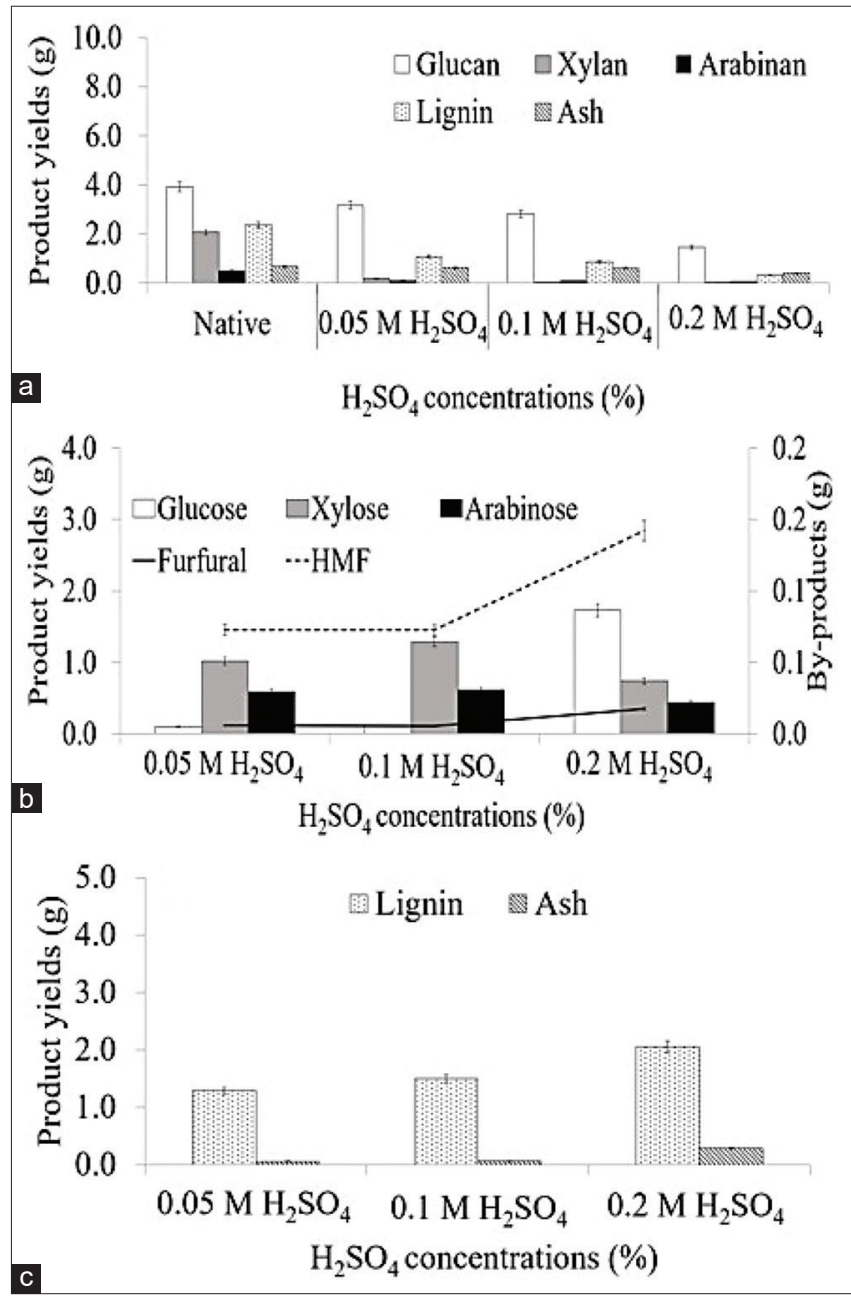

Fig 3. Effect of $\mathrm{H}_{2} \mathrm{SO}_{4}$ concentration on on EPFB components (a) solid phase (b) aqueous phase (c) organic phase. 
previous study, the results obtained from this work showed higher product yields and purity.

\section{Characterization of Lignin Recovery from Optimal Condition}

FT-IR analysis of commercial kraft lignin and recovered lignin

The FT-IR analysis was done mainly to identify the presence of functional groups present in commercial kraft lignin and recovered lignin (Fig.4). It shows the FT-IR spectra of recovered lignin (spectrum a) and commercial kraft lignin (spectrum b). The recovered lignin and commercial lignin illustrated the vibration of hydroxyl group $(\mathrm{O}-\mathrm{H})$ in phenolic and aliphatic compounds at 3288 and $3330 \mathrm{~cm}-1$ (Gonultas and candan, 2018). The vibrations at $1734 \mathrm{~cm}-1$ were related to $\mathrm{C}=\mathrm{O}$ stretching of carbonyl group (Matthews et al., 2016). The peak at $1682 \mathrm{~cm}-1$ were associated to carbonyl group. The fingerprint region between $1510 \mathrm{~cm}-1$ to $1460 \mathrm{~cm}-1$ indicates that aromatic carbon atoms absorption region (Florian et al., 2019). The vibration of syringyl group (S-unit) was at $1300 \mathrm{~cm}-1$ in chemical structure. The bands at $1200 \mathrm{~cm}-1$ indicates that these components were guaiacy group (G-unit). The chemical changes in band $1120 \mathrm{~cm}-1$ are assigned to the C-O stretching of syringyl and guaiacyl (Nadezhda et al., 2009). The fingerprint region between $1028 \mathrm{~cm}-1$ and $1026 \mathrm{~cm}-1$ comprises bands assigned to $\mathrm{C}-\mathrm{O}$ vibrations
(Samanta et al., 2018). In addition, the vibrations at 899$897 \mathrm{~cm}-1$ were related to $\mathrm{CH}$ out of plane deformation in lignin structure.

\section{Molecular weight distribution of lignin}

Molecular weight distribution of lignin samples is showed in Table 1. GPC analysis was selected to determine the weight average molecular weight $\left(\mathrm{M}_{\mathrm{w}}\right)$, number-average molecular weight $\left(\mathrm{M}_{\mathrm{n}}\right)$ and polydispersity index (PDI) of recovered lignin, comparing with commercial kraft lignin. The average $M_{w}$ and $M_{n}$ of recovered lignin were 2528 $\mathrm{Da}$ and $1550 \mathrm{Da}$, respectively. This related to PDI of 1.63. The result showed that the similar particle size of recovered lignin after fractionation process. The average $\mathrm{M}_{\mathrm{w}}$ and $\mathrm{M}_{\mathrm{n}}$ of commercial kraft lignin were $2950 \mathrm{Da}$ and $1650 \mathrm{Da}$, respectively, with PDI of 1.78. It was reported that the commercial lignin indicated higher distribution of molecular weight than that of recovered lignin (Table 1). According to the previous study, recovered lignin from

Table 1: Molecular weight distribution of the commercial kraft lignin and the recovered lignin

\begin{tabular}{lccc}
\hline Sample & $\mathbf{M w}^{\mathrm{a}}(\mathrm{g} / \mathrm{mol})$ & $\mathbf{M n}^{\mathrm{b}}(\mathrm{g} / \mathrm{mol})$ & $\mathrm{Mw} / \mathrm{Mn}(\mathrm{PDI})^{\mathrm{c}}$ \\
\hline $\begin{array}{l}\text { Commercial kraft } \\
\text { lignin }\end{array}$ & 2528 & 1550 & 1.63 \\
Recovered lignin & 2950 & 1650 & 1.78
\end{tabular}

aWeight-average molecular weight (Mw), ${ }^{b}$ Number-average molecular weight (Mn), ,Polydispersity index (PDI)

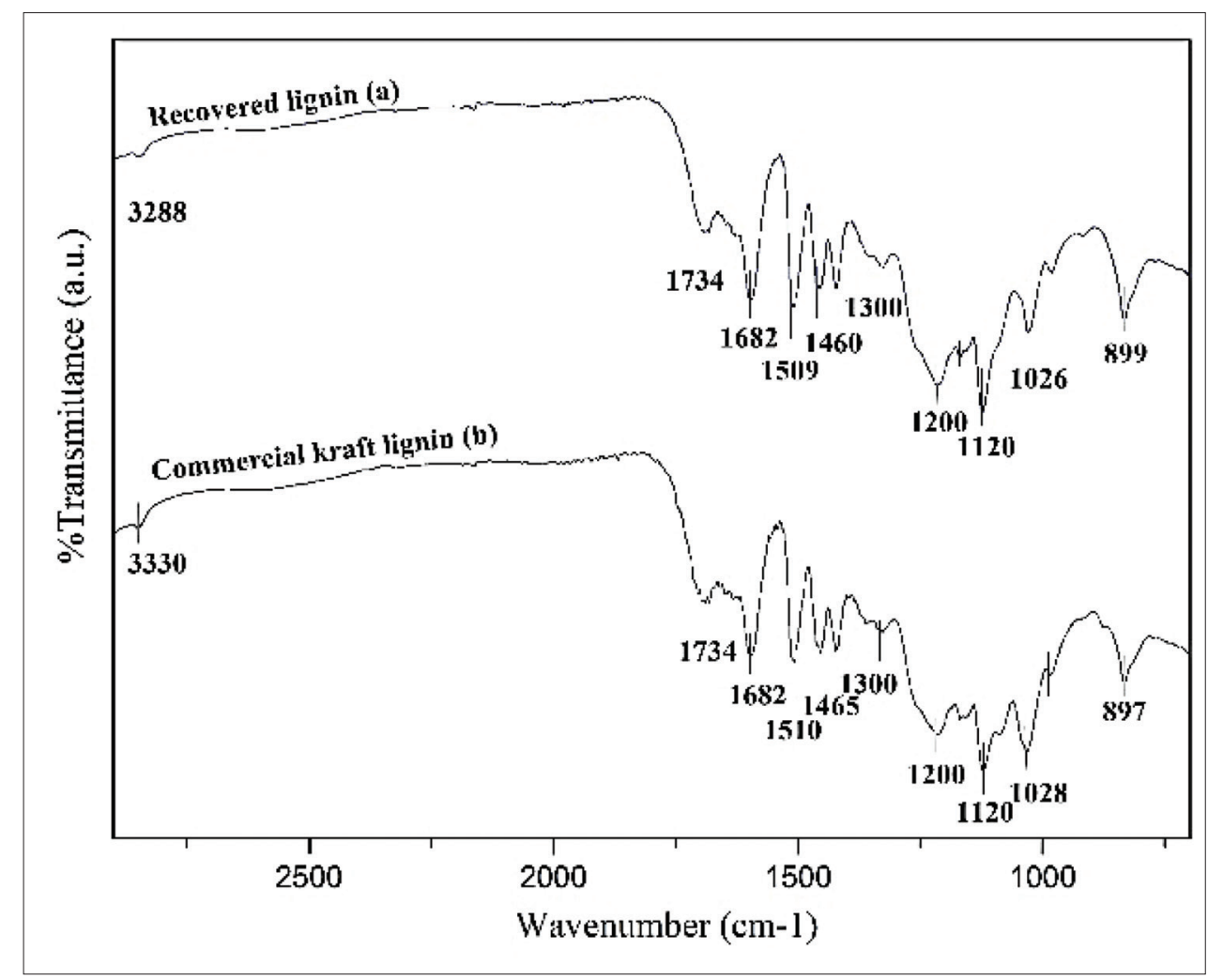

Fig 4. (FT-IR) spectra of (a) recovered lignin from the fractionation process under the optimal conditions in the comparison with (b) commercial kraft lignin. 


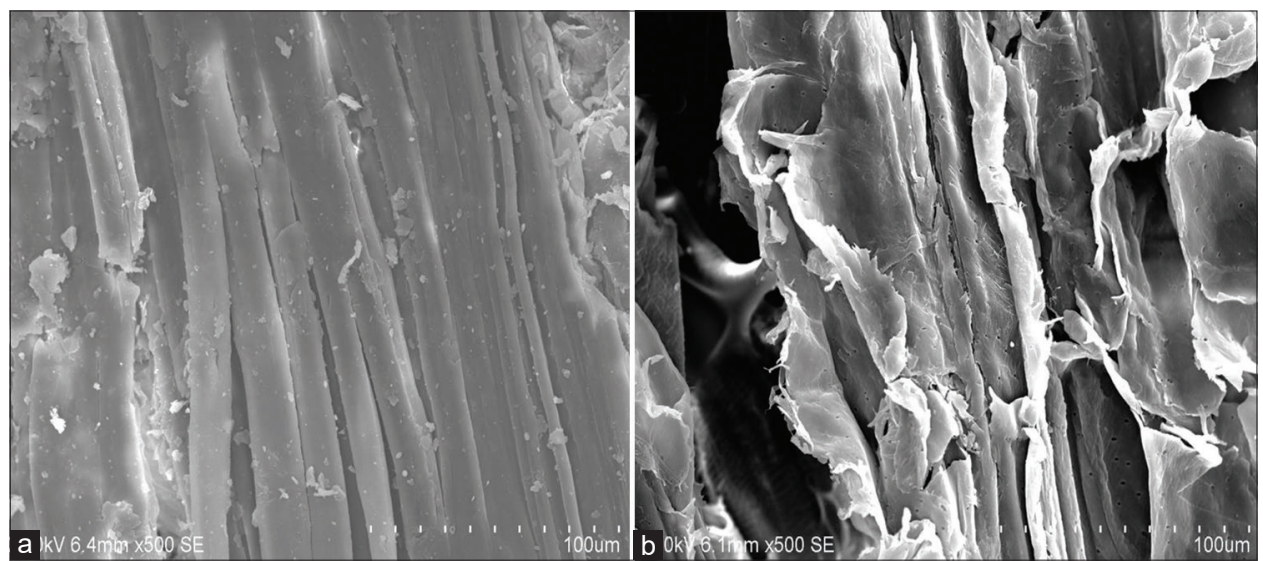

Fig 5. Scanning electron micrographs of native EPFB. (a) Native EPFB; (b) EPFB isolated under optimal condition.

Table 2: Surface area and crystallinity index of native EPFB
and solid residues from optimal condition
\begin{tabular}{|lcc}
\hline Sample & Surface area $\left(\mathrm{m}^{2} / \mathrm{g}\right)$ & Degree of crystallinity (\%) \\
\hline Native EPFB & 2.7 & 58.1 \\
Isolated solid & 4.8 & 62.7 \\
\hline
\end{tabular}

sugarcane bagasse under organosolv fractionation process using ternary mixture (water/ethanol/ethyl acetate/r) showed that PDI of recovered lignin from organic phase (1.663) is not significant differences to PDI of original lignin. (Suriyacha et al., 2017). Moreover, in regard to the previous report, lignin extraction using solvothermal process showed less PDI value of lignin recovery, 1.66, in the comparison with commercial lignin 2.39 (Liu et al., 2019). However, the low molecular of lignin has potential applications in the bio-materials, biorefinery industry and environmental fields (Iravani and Varma, 2020).

\section{Characterization of isolated solid from optimal condition}

Physical structure modifications of EPFB were isolated by solvothermal under the optimal condition, as can be seen in Fig. 5. Being shown by SEM, the EPFB surface was intact and smooth with a compact and orderly arranged structure. The cellulose and hemicellulose were tightly wrapped by lignin before the fractionation. After being under optimal condition, the surface became rough with large amounts of voids, and the wrapping structure was broken. These changes in the biomass microstructures were similar to those observed in various biomass, which were isolated by various methods (Ciesielski et al., 2015).

Crystallinity and surface area of the isolated EPFB are also considered as important factors, influencing the efficiency of solvothermal fractionation (Table 2). Increased crystallinity (CrI) (62.7\%) was obtained for EPFB, and isolated by solvothermal fractionation under the optimal condition $\left(180^{\circ} \mathrm{C}, 15 \mathrm{~min}\right)$, comparing with native EPFB $(58.1 \%)$. The increases in $\mathrm{CrI}$ were corresponded to effects of solvothermal on the removal of the amorphous xylan and lignin fractions, while it showed less effect on the disruption of the highly crystalline cellulose (Fan et al., 2016). Increases in biomass crystallinity were exhibited in various biomasses, which was isolated byusing hydrothermal fractionation in the absence and presence of acid promoters and also other fractionation methods, e.g., aqueous ammonia pretreatment (Sun et al., 2018, Kim et al., 2013). Fractionation of EPFB resulted in increasing surface area compared to the native EPFB $\left(2.7 \mathrm{~m}^{2} / \mathrm{g}\right)$. The maximum surface area, $4.8 \mathrm{~m}^{2} / \mathrm{g}$, was observed with the reaction of $180^{\circ} \mathrm{C}$ for $15 \mathrm{~min}$.

\section{CONCLUSION}

The solvothermal fractionation was showed as an effective method for fractionation of EPFB. The results indicated $75.9 \%, 17.8 \%$, and $13.7 \%$ of the maximum glucan yields, pentose yields, and lignin yields, respectively. These were combined in the liquid phase from the fractionation step with less amount of inhibitory by-product formation, which was lower than the level for ethanogenic yeast. The $\mathrm{H}_{2} \mathrm{SO}_{4}$ promoter possesses excellent ether linkage cleavage capability. The lowest molecular weight was found in recovery lignin residues $(2528 \mathrm{~g} / \mathrm{mol})$, being suspected because co-extracted carbohydrate residues bounded to extracted lignin macromolecules. These results allowed us to establish the effective solvothermal fractionation for lignin isolation from EPFB. However, depending on the application of the extracted lignin, the presence $\mathrm{H}_{2} \mathrm{SO}_{4}$ promoter will require additional purification treatments.

\section{ACKNOWLEGMENTS}

This project was financially supported by the research grants from the Thailand Research Fund and the Office of the Higher Education Commission (MRG6080162). 
Nopparat Suriyachai was supported by Unit of Excellence (UOE63006) from the University of Phayao.

\section{Author's contributions}

Nopparat Suriyachai: review \& editing, Conceptualization, Methodology

Punjarat Khongchamnan: Writing - original draft, Writing, Formal analysis, Methodology

Navadol Laosiripojana: Visualization

Torpong Kreetachat: Validation

Verawat Champreda; Visualization

Saksit Imman: Investigation, Supervision, research formulation, Visualization, Writing - review \& editing.

\section{REFERENCES}

Ahorsu, R., F. Medina and M. Constantí. 2018. Significance and challenges of biomass as a suitable feedstock for bioenergy and biochemical production. A review. Energies. 11: 3366.

Arora, A., P. Nandal, J. Singh and M. L. Verma. 2020. Nanobiotechnological advancements in lignocellulosic biomass pretreatment. Mater. Sci. Energy Technol. 3: 308-318.

Brodeur, G., E. Yau, K. Badal, J. Collier, K. B. Ramachandran and S. Ramakrishnan. 2011. Chemical and physicochemical pretreatment of lignocellulosic biomass: A review. Enzyme Res. 2011: 787532.

Cao, J., G. Xiao, X. Xu, D. Shen and B. Jin. 2013. Study on carbonization of lignin by TG-FTIR and high-temperature carbonization reactor. Fuel Process. Technol. 106: 41-47.

Cheng, S., C. Wilks, Z. Yuan, M. Leitch and C. Xu. 2012. Hydrothermal degradation of alkali lignin to bio-phenolic compounds in sub/ supercritical ethanol and water-ethanol co-solvent. Polym. Degrad. Stab. 97: 839-848.

Chang, S. H. 2014. An overview of empty fruit bunch from oil palm as feedstock for bio-oil production. Biomass Bioenergy. 62: 174-181.

Ciesielski, P. N., M. F. Crowley, M. R. Nimlos, A. W. Sanders, G. M. Wiggins, D. Robichaud and T. D. Foust. 2015. Biomass particle models with realistic morphology and resolved microstructure for simulations of intraparticle transport phenomena. Energy Fuels. 29: $242-254$.

Delbecq, F., Y. Wang, A. Muralidhara, K. El Ouardi, G. Marlair and C. Len. 2018. Hydrolysis of hemicellulose and derivatives-a review of recent advances in the production of furfural. Front. Chem. 6: 146

Fan, S., P. Zhang, F. Li, S. Jin, S. Wang and S. Zhou. 2016. A review of lignocellulose change during hydrothermal pretreatment for bioenergy production. Curr. Org. Chem. 20: 2799-2809.

Florian, T. D. M., N. Villani, M. Aguedo, N. Jacquet, H. G. Thomas, P. Gerin and A. Richel. 2019. Chemical composition analysis and structural features of banana rachis lignin extracted by two organosolv methods. Ind. Crops Prod. 132: 269-274.

Gonultas, O. and Z. Canda. 2018. Chemical characterization and ftir spectroscopy of thermally compressed eucalyptus wood panels. Maderas Cien. Tecnol. 20: 431-442.

Grande, P. M., D. Weidener, S. Dietrich, M. Dama, M. Bellof, R. Maas and P. D. de Maria. 2019. OrganoCat fractionation of empty fruit bunches from palm trees into lignin, sugars, and celluloseenriched pulp. ACS Omega. 4: 14451-14457.

Hafyan, R. H., L. K. Bhullar, S. Mahadzir, M. R. Bilad, N. A. H. Nordin,
M. D. H. Wirzal and B. Abdullah. 2020. Integrated biorefinery of empty fruit bunch from palm oil industries to produce valuable biochemicals. Processes. 8: 868.

Hassan, M. A., M. A. A. Farid, Y. Shirai, H. Ariffin, M. R. Othman, M. H. Samsudin and M. Y. Hasan. 2019. Oil Palm biomass biorefinery for sustainable production of renewable materials. Biotechnol. J. 14: e1800394.

Iravani, S. and R. S. Varma. 2020. Greener synthesis of lignin nanoparticles and their applications. Green Chem. 22: 612-636.

Jasiukaitytè-Grojzdek, E., M. Huš, M. Grilc and B. Likozar. 2020. Acid-catalysed a-O-4 aryl-ether bond cleavage in methanol/ (aqueous) ethanol: Understanding depolymerisation of a lignin model compound during organosolv pretreatment. Sci. Rep. 10: 11037-11037.

Kim, S., J. M. Park, J. W. Seo and C. H. Kim. 2012. Sequential acid-/ alkali-pretreatment of empty palm fruit bunch fiber. Bioresour. Technol. 109: 229-233.

Kim, S. B., S. J. Lee, J. H. Lee, Y. R. Jung, L. P. Thapa, J. S. Kim and S. W. Kim. 2013. Pretreatment of rice straw with combined process using dilute sulfuric acid and aqueous ammonia. Biotechnol. Biofuels. 6: 109-109.

Klamrassamee, T., V. Champreda, V. Reunglek and N. Laosiripojana. 2013. Comparison of homogeneous and heterogeneous acid promoters in single-step aqueous-organosolv fractionation of eucalyptus wood chips. Bioresour Technol. 147: 276-284.

Lee, K. M., M. F. Zanil, K. K. Chan, Z. P. Chin, Y. C. Liu and S. Lim. 2020. Synergistic ultrasound-assisted organosolv pretreatment of oil palm empty fruit bunches for enhanced enzymatic saccharification: An optimization study using artificial neural networks. Biomass Bioenergy. 139: 105621.

Mathew, A. K., A. Abraham, K. K. Mallapureddy and R. K. Sukumaran. 2018. Lignocellulosic biorefinery wastes, or resources. In: Waste Biorefinery. pp. 267-297.

Matthews, S. 2016. Structural Changes of Rice Straw Pre-Treated with Paenibacillus and Aspergillus fumigatus. Agric. Food Res. 5: 1-8.

Medina, J. D. C., A. Woiciechowski, A. Z. Filho, P. S. Nigam, L. P. Ramos and C. R. Soccol. 2016. Steam explosion pretreatment of oil palm empty fruit bunches (EFB) using autocatalytic hydrolysis: A biorefinery approach. Bioresour. Technol. 199: 173-180.

Nadezhda, M. L., V. E. Baulin, A. Y. Tsivadze, E. N. Pyatova, I. S. Ivanova, Y. A. Velikodny and V. V. Chernyshev. 2009. Ni(II), $\mathrm{Co}(\mathrm{II}), \mathrm{Cu}(\mathrm{II}), \mathrm{Zn}(\mathrm{II})$ and $\mathrm{Na}(\mathrm{I})$ Complexes of a Hybrid Ligand 4'-(4"'-Benzo-15-Crown-5)-Methyloxy-2, 2': 6', 2"-Terpyridine, Dalton Transactions.

Nurfahmi, Ong, H. C., B. M. Jan, W. Tong, H. C. Fauzi and W. H. Chen. 2016. Effects of organosolv pretreatment and acid hydrolysis on palm empty fruit bunch (PEFB) as bioethanol feedstock. Biomass Bioenergy. 95: 78-83.

Pangsang, N., U. Rattanapan, A. Thanapimmetha, P. Srinopphakhun, C. G. Liu, X. Q. Zhao and C. Sakdaronnarong. 2019. Chemicalfree fractionation of palm empty fruit bunch and palm fiber by hot-compressed water technique for ethanol production. Energy Rep. 5: 337-348.

Perera, F. 2017. Pollution from fossil-fuel combustion is the leading environmental threat to global pediatric health and equity: Solutions exist. Int. J. Environ. Res. Public Health. 15: 16.

Samanta, A. K., G. Basu and L. Mishra. 2018. Role of major constituents of coconut fibres on absorption of ionic dyes. Ind. Crops Prod. 117: 20-27.

Sebastien, N. O., I. Ziegler-Devin, R. Safou-Tchima and N. Brosse. 2019. Homolytic and heterolytic cleavage of beta-ether linkages 
in hardwood lignin by steam explosion. Agric. Food Chem. 67: 5989.

Segal, L., J. J. Creely, A. E. Jr. Martin and C. M. Conrad. 1959. An empirical method for estimating the degree of crystallinity of native cellulose using the X-ray diffractometer. Text. Res. J. 29: 786-794.

Sluiter, A., B. Hames, R. Ruiz, C. Scarlata, J. Sluiter, D. Templeton and D. Crocker. 2008. Determination of Structural Carbohydrates and Lignin in Biomass NREL/TP-510-42618, Laboratory Analytical Procedure (LAP).

Sun, S., F. Liu, L. Zhang and X. Fan. 2018. One-step process based on the order of hydrothermal and alkaline treatment for producing lignin with high yield and antioxidant activity. Ind. Crops Prod. 119: 260-266.

Suriyachai, N., V. Champreda, C. Sakdaronnarong, A. Shotipruk and N. Laosiripojana. 2017. Sequential organosolv fractionation/ hydrolysis of sugarcane bagasse: The coupling use of heterogeneous $\mathrm{H} 3 \mathrm{PO} 4$-activated carbon as acid promoter and hydrolysis catalyst. Renew. Energy. 113: 1141-1148.

Suriyachai, N., V. Champreda, N. Kraikul, W. Techanan and N.
Laosiripojana. 2017. Fractionation of lignocellulosic biopolymers from sugarcane bagasse using formic acid-catalyzed organosolv process. 3 Biotech. 8: 221.

Tan, L., M. Wang, X. Li, H. Li, J. Zhao, Y. Qu and S. K. Loh. 2016. Fractionation of oil palm empty fruit bunch by bisulfite pretreatment for the production of bioethanol and high value products. Bioresour. Technol. 200: 572-578.

Takkellapati, S., T. Li and M. A. Gonzalez. 2018. An overview of biorefinery derived platform chemicals from a cellulose and hemicellulose biorefinery. Clean Technol. Environ. Policy. 20: 1615-1630.

Tarasov, D., M. Leitch and P. Fatehi. 2018. Lignin-carbohydrate complexes: Properties, applications, analyses, and methods of extraction: A review. Biotechnol. Biofuels. 11: 269.

Wu, J. I., Y. Mo, F. A. Evangelista and P. von Rague Schleyer. 2012. Is cyclobutadiene really highly destabilized by antiaromaticity. Chem. Commun. (Camb). 48: 8437-8439.

Zhang, X., D. Zhang, Z. Sun, L. Xue, X. Wang and Z. Jiang. 2016. Highly efficient preparation of HMF from cellulose using temperature-responsive heteropolyacid catalysts in cascade reaction. Appl. Catal. B Environ. 196: 50-56. 